\title{
The Clinical Impact of Body Mass Index on Breast Cancer in Korea: A Nationwide Population-Based Cohort Study
}

\author{
Jae Hwan Jeong, M.D., Hak Min Lee, M.D., Hai Young Son, M.D., Ilkyun Lee, M.D., Ph D. \\ Department of Surgery, Catholic Kwandong University International St. Mary's Hospital, Catholic Kwandong University College of Medicine, Incheon, \\ Korea
}

Purpose: Although increasing body mass index (BMI) is regarded as a potential risk factor for breast cancer (BC) in postmenopausal women, research on premenopausal women has produced conflicting results. We investigated the association between $\mathrm{BMl}$ and $\mathrm{BC}$ according to menopausal status in Korean. Methods: We analyzed clinical data from 186,835 women aged 20 years or older between 2003 and 2008 using a sample cohort from the national database in Korea. We identified women newly diagnosed with $\mathrm{BC}$ and estimated the risk of $\mathrm{BC}$ according to BMl $\left(\mathrm{kg} / \mathrm{m}^{2}\right)$. Subjects were categorized into five groups according to World Health Organization recommendations for Asians: underweight, <18.5 kg/m²; normal weight, $18.5-22.9 \mathrm{~kg} / \mathrm{m}^{2}$; overweight, $23.0-24.9 \mathrm{~kg} / \mathrm{m}^{2}$; obese class I, 25.0-29.9 kg/ $/ \mathrm{m}^{2}$; and obese class II, $\geq 30.0 \mathrm{~kg} / \mathrm{m}^{2}$. Results: 1,372 women in the cohort were newly diagnosed with BC. A positive relationship between BMl and BC was detected and the hazard ratio in each group compared with the normal weight group was 0.57 (95\% Cl, 0.42-0.78), 1.27 (1.11-1.45), 1.25 (1.09-1.44), and 1.28 (0.95-1.73), respectively. BMI was determined to be an important risk factor for BC in postmenopausal women (p for trend was 0.015 ). We failed to find a significant correlation between $\mathrm{BMI}$ and $\mathrm{BC}$ in premenopausal women. Conclusion: $\mathrm{BMI}$ is positively associated with $\mathrm{BC}$ in postmenopausal Korean women.

Key Words: Body mass index, Breast neoplasms, Incidence, Obesity

\section{INTRODUCTION}

Breast cancer $(\mathrm{BC})$ is the second most common cancer in Korean women, and its incidence has significantly increased in recent years $[1,2]$. The crude incidence rate (IR) of Korean women with BC in 2012 was 70.7 cases per 100,000 women, which was more than three times the rate in 1999. This increasing trend seems to be associated with westernization of lifestyle and diet, that is, excessive nutritional intake and lower physical activity are increasing as Korea's economy develops [2].

Consistent with the rapid socioeconomic development, the obesity rate has been increasing rapidly in Korea [3]. The overall prevalence of obesity, as defined by a body mass index (BMI) $\geq 25.0 \mathrm{~kg} / \mathrm{m}^{2}$, in Korean women increased from $18.0 \%$ in 1995 to $29.4 \%$ in 2001 . Obesity is a major health problem in several countries including Korea because it

Correspondence: Ilkyun Lee, M.D., Ph D.

Department of Surgery, Catholic Kwandong University International St. Mary's Hospital, Catholic Kwandong University College of Medicine, 25 Simgok-ro 100beon-gil, Seo-gu, Incheon 22711, Korea.

Tel: +82-32-290-3271, Fax: +82-32-290-3879, E-mail: iklee68@gmail.com

This work was supported by the research fund of Catholic Kwandong University International St. Mary's Hospital (CKURF-201604830001).

Received: Oct 29, 2019 Revised: Nov 7, 2019 Accepted: Feb 18, 2020 contributes to increasing rates of not only obesity-related morbidities, such as cardiovascular disease, but also various types of cancers [4].

An association between obesity and $\mathrm{BC}$ has been demonstrated in several studies and it is generally accepted that obesity is a risk factor for BC in postmenopausal women [5]. However, some studies have provided conflicting results regarding obesity as a risk factor for $\mathrm{BC}$ in premenopausal women [6,7]. Korean women exhibit more distinctive demographic differences compared with Western women, including a lower obesity rate and relatively dense breasts. Additionally, approximately half of all BC in Korea are observed in premenopausal women; hence, the effects of obesity in the development of BC in Korean women have been paid careful attention. We investigated the association between BMI and BC in Korean women according to menopausal status using a nationwide population-based cohort

\section{METHODS}

In the present study, we used the National Health Insurance Service (NHIS) National Sample Cohort, a population-based retrospective cohort in South Korea. The NHIS is a single-payer organization that 
provides medical services for all residents in Korea. It maintains national records, including patient demographics, medical use/transaction information, insurers' payment coverage, and a patient deduction and claim database, which covers diagnosis, prescriptions, and consultation statements [8]. The NHIS constructed a representative sample database with a substantial volume of representative information that is exempted from privacy regulations for research and policy development [9]. From the target population, a representative sample cohort of 1,025,340 subjects was randomly selected. Members of the cohort, which represented $2.2 \%$ of the total eligible Korean population in 2002, were followed up for 11 years until 2013, unless a subject was disqualified due to death or emigration. From this cohort, we selected women aged at least 20 years who had received at least one regular medical checkup between 2003 and 2008. We excluded patients who reported a diagnosis of $\mathrm{BC}$ before 2003. As a result, 186,835 subjects were included in the present study.

BMI was calculated as the subject's weight $(\mathrm{kg})$ divided by the square of her height $\left(\mathrm{m}^{2}\right)$ measured at regular medical checkups. Subjects were categorized into one of five groups according to BMI following the World Health Organization recommendations for Asians: underweight, $<18.5 \mathrm{~kg} / \mathrm{m}^{2}$; normal weight, $18.5-22.9 \mathrm{~kg} / \mathrm{m}^{2}$; overweight, $23.0-24.9 \mathrm{~kg} / \mathrm{m}^{2}$; obese class I, $25.0-29.9 \mathrm{~kg} / \mathrm{m}^{2}$; and obese class II, $\geq 30.0 \mathrm{~kg} / \mathrm{m}^{2}[10,11]$. Laboratory examinations with serum samples were also performed during weight measurement. Detailed histories of smoking habits, alcohol consumption, and physical activity (including amount and frequency) were obtained using questionnaires. We performed statistical analyses using the simplified status classifications of smoking (current, ex-smoker, or non-smoker), alcohol consumption (drinker or non-drinker), and regular exercise, which was defined as strenuous physical activity that was performed for at least $20 \mathrm{~min}$ per day (yes or no). A subject's socioeconomic status was dichotomized at the lower $20 \%$. Blood samples were drawn after an overnight fast and measured to assess the serum levels of glucose and total cholesterol. Hospitals where these health examinations were performed were certified by the NHIS and subjected to regular quality controls. The primary endpoint of this study was BC development, defined in those who were registered with a C50 code according to the International Classification of Disease, 10th Revision, within 30 days of a breast biopsy. Individuals were followed up from baseline to the date of death or until December 31, 2013, whichever came first. The baseline was the first date the individuals received a standardized regular medical checkup. All subjects provided informed consent for inclusion before they participated in the study. The study was conducted in accordance with the Declaration of Helsinki, and the protocol was approved by the Institutional Review Board of Catholic Kwandong University of Korea (IRB No. IS16RISI0034).

The association between $\mathrm{BMI}$ and $\mathrm{BC}$ risk was analyzed using a Cox proportional hazard regression model. Variables used for the multivariate models included age, smoking habits, alcohol consumption, exercise, and patient's income. Interactions between variables were tested. Kaplan-Meier curves were plotted and compared using a log-rank test. Statistical analyses were performed using Statistical Analysis System (SAS) version 9.4 (SAS Institute, Cary, NC, USA). A two-sided $p$-value $<0.05$ was considered statistically significant.

\section{RESULTS}

Of the study's 186,835 subjects, 11,983 (6.4\%), 86,803 (46.5\%), 39,996 (21.4\%), 42,377 (22.7\%), and 5,676 (3.0\%) women were classified as underweight, normal weight, overweight, obese class I, and obese class II, respectively. The baseline characteristics of each group are shown in Table 1. Only approximately $16 \%$ of the underweight group was aged 50 years or older, compared with greater than $50 \%$ of the overweight or obesity group. Blood pressure and fasting glucose and blood cholesterol level increased proportionally with BMI. Higher incidences of hypertension (HTN), diabetes mellitus (DM), and dyslipidemia were observed in women with higher BMIs than in women with lower BMIs. The underweight group was associated with a high frequency of smoking, low alcohol uptake, and low exercise.

During an 84-month follow-up period, 1,372 women were newly diagnosed with $\mathrm{BC}$. The incidence of $\mathrm{BC}$ in each group is shown in Table 2. The IR of BC per 1,000 subjects during the follow-up duration increased with increasing BMI: 0.45 in the underweight, 0.84 in the normal weight, 1.11 in the overweight, 1.10 in the obese class I, and 1.10 in the obese class II. This association was observed in both premenopausal and postmenopausal women (IR, 0.45, 0.82, 1.24, 1.23, and 1.04 in each group of premenopausal women and 0.45, 0.86, 0.98, 1.02 , and 1.15 in each group of postmenopausal women, respectively).

A Cox regression analysis also showed that increasing BMI was positively associated with BC development (Table 3, Figure 1). Com- 
Table 1. Baseline characteristics of the study population

\begin{tabular}{|c|c|c|c|c|c|c|}
\hline Characteristic & $\begin{array}{l}\text { Underweight } \\
\begin{array}{c}\left(<18.5 \mathrm{~kg} / \mathrm{m}^{2}\right) \\
\mathrm{n}=11,983 \\
\text { No. }(\%)\end{array}\end{array}$ & $\begin{array}{c}\text { Normal weight } \\
\left(18.5-22.9 \mathrm{~kg} / \mathrm{m}^{2}\right) \\
\mathrm{n}=86,803 \\
\text { No. }(\%)\end{array}$ & $\begin{array}{c}\text { Overweight } \\
\begin{array}{c}\left(23-24.9 \mathrm{~kg} / \mathrm{m}^{2}\right) \\
\mathrm{n}=39,996 \\
\text { No. }(\%)\end{array}\end{array}$ & $\begin{array}{c}\text { Obese, class I } \\
\begin{array}{c}\left(25-29.9 \mathrm{~kg} / \mathrm{m}^{2}\right) \\
\mathrm{n}=42,377 \\
\text { No. }(\%)\end{array}\end{array}$ & $\begin{array}{c}\text { Obese, class II } \\
\begin{array}{c}\left(\geq 30 \mathrm{~kg} / \mathrm{m}^{2}\right) \\
n=5,676\end{array} \\
\text { No. }(\%)\end{array}$ & $p$-value \\
\hline Age (yr) & & & & & & $<0.001$ \\
\hline$<50$ & $10,012(83.5)$ & $60,714(69.9)$ & $19,317(48.3)$ & $15,971(37.7)$ & $2,286(40.3)$ & \\
\hline$\geq 50$ & $1,971(16.5)$ & $26,089(30.1)$ & $20,679(51.7)$ & $26,406(62.3)$ & $3,390(59.7)$ & \\
\hline Mean age $(y r)^{*}$ & $35.3 \pm 15.9$ & $42.8 \pm 15.0$ & $50.3 \pm 13.2$ & $53.3 \pm 12.7$ & $52.0 \pm 13.7$ & \\
\hline Height $(\mathrm{cm})^{*}$ & $159.2 \pm 6.5$ & $157.3 \pm 6.2$ & $155.4 \pm 5.9$ & $154.5 \pm 5.9$ & $154.3 \pm 6.5$ & $<0.001$ \\
\hline Weight $(\mathrm{kg})^{*}$ & $44.6 \pm 4.1$ & $52 \pm 4.7$ & $58 \pm 4.5$ & $64.1 \pm 5.7$ & $76.6 \pm 9.0$ & $<0.001$ \\
\hline Mean BMI $\left(\mathrm{kg} / \mathrm{m}^{2}\right)^{*}$ & $17.6 \pm 0.8$ & $21 \pm 1.2$ & $24 \pm 0.6$ & $26.8 \pm 1.3$ & $32.1 \pm 2.8$ & $<0.001$ \\
\hline Systolic blood pressure $(\mathrm{mmHg})^{*}$ & $112 \pm 14.5$ & $116.7 \pm 15.8$ & $123.1 \pm 17.1$ & $128 \pm 17.8$ & $133.1 \pm 17.7$ & $<0.001$ \\
\hline Diastolic blood pressure $(\mathrm{mmHg})^{*}$ & $70.3 \pm 9.5$ & $72.8 \pm 10.3$ & $76.3 \pm 10.9$ & $79 \pm 11.2$ & $82.2 \pm 11.3$ & $<0.001$ \\
\hline Hypertension (yes) & $966(8.1)$ & $13,516(15.6)$ & $11,810(29.5)$ & $18,088(42.7)$ & $3,223(56.8)$ & $<0.001$ \\
\hline Fasting glucose $(\mathrm{mmol} / \mathrm{L})^{*}$ & $87.7 \pm 17.9$ & $90.6 \pm 21.4$ & $94.9 \pm 25.4$ & $98.6 \pm 29.1$ & $103.1 \pm 31.0$ & $<0.001$ \\
\hline Diabetes Mellitus (yes) & $258(2.2)$ & $3,169(3.7)$ & $2,993(7.5)$ & $4,850(11.4)$ & $978(17.2)$ & $<0.001$ \\
\hline Cholesterol $(\mathrm{mmol} / \mathrm{L})^{*}$ & $175.2 \pm 31.4$ & $186.2 \pm 35.4$ & $198.7 \pm 38.4$ & $204.9 \pm 39.3$ & $208.1 \pm 39.1$ & $<0.001$ \\
\hline Dyslipidemia (yes) & $467(3.9)$ & $8,080(9.3)$ & $7,066(17.7)$ & $10,133(23.9)$ & $1,607(28.3)$ & $<0.001$ \\
\hline Smoking status & & & & & & $<0.001$ \\
\hline None & $11,239(93.8)$ & $82,745(95.3)$ & $38,615(96.6)$ & $40,875(96.5)$ & $5,366(94.5)$ & \\
\hline Ex-smoker & $139(1.2)$ & $705(0.8)$ & $236(0.6)$ & $235(0.5)$ & $40(0.7)$ & \\
\hline Current smoker & $605(5.0)$ & $3,353(3.9)$ & $1,145(2.8)$ & $1,267(3.0)$ & $270(4.8)$ & \\
\hline Alcohol drinking & & & & & & $<0.001$ \\
\hline None & $7,494(62.5)$ & $59,592(68.7)$ & $30,526(76.3)$ & $33,583(79.3)$ & $4,379(77.2)$ & \\
\hline 1-2 times/week & $2,775(23.2)$ & $15,827(18.2)$ & $5,350(13.4)$ & $4,790(11.3)$ & 670 (11.8) & \\
\hline$\geq 3$ times/week & $1,714(14.3)$ & $11,384(13.1)$ & $4,120(10.3)$ & $4,004(9.4)$ & $627(11.0)$ & \\
\hline Regular exercise ${ }^{\dagger}$ (yes) & $2,572(21.5)$ & $30,171(34.8)$ & $15,789(39.5)$ & $16,050(37.9)$ & $1,979(34.9)$ & $<0.001$ \\
\hline Income (lower 20\%) & $2,486(20.8)$ & $18,005(20.7)$ & $8,066(20.2)$ & $8,696(20.5)$ & $1,243(21.9)$ & 0.019 \\
\hline
\end{tabular}

$\mathrm{BMI}=$ body mass index.

*Mean $\pm \mathrm{SD} ;{ }^{\dagger}$ Strenuous physical activity that was performed for at least 20 min per day.

Table 2. Development and incidence of breast cancer rates according to body mass index group

\begin{tabular}{|c|c|c|c|c|c|c|c|c|c|}
\hline \multirow{2}{*}{ Variable } & \multicolumn{3}{|c|}{ Total } & \multicolumn{3}{|c|}{ Age $<50$} & \multicolumn{3}{|c|}{ Age $\geq 50$} \\
\hline & Event & Duration (yr)* & $\mathbb{I R}^{\dagger}$ & Event & Duration $(\mathrm{yr})^{*}$ & $\mathbb{I R}^{\dagger}$ & Event & Duration $(\mathrm{yr})^{*}$ & $\mathbb{I R}^{\dagger}$ \\
\hline Underweight & 42 & $93,178.11$ & 0.45 & 35 & $77,773.18$ & 0.45 & 7 & $15,404.93$ & 0.45 \\
\hline Normal weight & 569 & $680,023.08$ & 0.84 & 394 & $475,761.73$ & 0.83 & 175 & $204,261.35$ & 0.86 \\
\hline Overweight & 348 & $314,688.43$ & 1.10 & 188 & $152,129.93$ & 1.24 & 160 & $162,558.49$ & 0.98 \\
\hline Obese, class I & 365 & $332,391.29$ & 1.10 & 154 & $125,112.63$ & 1.23 & 211 & $207,278.66$ & 1.02 \\
\hline Obese, class II & 48 & $43,459.18$ & 1.10 & 18 & $17,380.08$ & 1.04 & 30 & $26,079.10$ & 1.15 \\
\hline
\end{tabular}

*Person-years of observation (number of case $\times$ follow up period); ${ }^{\dagger}$ Incidence rate (per 1000) during follow-up period.

pared with the normal weight, the unadjusted hazard ratio (HR) of BC was 0.54 (95\% confidence interval [CI], 0.39-0.74) in the underweight, 1.32 (95\% CI, 1.16-1.51) in the overweight, 1.31 (95\% CI, 1.15$1.50)$ in the obese class I, and 1.32 (95\% CI, 0.99-1.78) in the obese class II ( $p$ for trend $<0.001$ ). When adjusting for age, smoking, drinking, exercise, and income, similar patterns were observed in all models $(p$ for trend $<0.001)$. The more detailed the BMI section was, the more closely an association between BMI and BC was observed ( $p$ for trend
$<0.001$, Figure 2).

According to Cox regression analysis, premenopausal women showed significantly increased unadjusted HR of BC according to increasing BMI (Table 3). Compared with the normal weight, the unadjusted HR was 0.54 (95\% CI, 0.39-0.77) in the underweight, 1.49 (95\% CI, 1.25-1.77) in the overweight, 1.49 (95\% CI, 1.23-1.79) in the obese class I, and 1.26 (95\% CI, 0.78-2.01) in the obese class II ( $p$ for trend $<0.001)$. However, adjusted HRs showed no statistically significant 
Table 3. Hazard ratios for development of breast cancer according to body mass index group

\begin{tabular}{|c|c|c|c|c|}
\hline \multirow{2}{*}{ Variable } & \multirow{2}{*}{ Group } & \multicolumn{3}{|c|}{ Hazard ratio $(95 \% \mathrm{Cl})$} \\
\hline & & Model ${ }^{*}$ & Model $2^{\dagger}$ & Model $3^{\ddagger}$ \\
\hline \multirow[t]{6}{*}{ Total } & Underweight & $0.54(0.39-0.74)$ & $0.56(0.41-0.76)$ & $0.57(0.42-0.78)$ \\
\hline & Normal weight & Reference & Reference & Reference \\
\hline & Overweight & $1.32(1.16-1.51)$ & $1.28(1.12-1.47)$ & $1.27(1.11-1.45)$ \\
\hline & Obese, class I & $1.31(1.15-1.50)$ & $1.26(1.10-1.44)$ & $1.25(1.09-1.44)$ \\
\hline & Obese, class II & $1.32(0.99-1.78)$ & $1.27(0.95-1.71)$ & $1.28(0.95-1.73)$ \\
\hline & $p$ for trend & $<0.001$ & $<0.001$ & $<0.001$ \\
\hline \multirow[t]{6}{*}{ Age $<50$} & Underweight & $0.54(0.39-0.77)$ & $0.87(0.61-1.23)$ & $0.87(0.61-1.23)$ \\
\hline & Normal weight & Reference & Reference & Reference \\
\hline & Overweight & $1.49(1.25-1.77)$ & $1.13(0.94-1.34)$ & $1.13(0.94-1.34)$ \\
\hline & Obese, class I & $1.49(1.23-1.79)$ & $1.06(0.88-1.28)$ & $1.06(0.88-1.29)$ \\
\hline & Obese, class II & $1.26(0.78-2.01)$ & $0.98(0.61-1.57)$ & $0.99(0.62-1.59)$ \\
\hline & $p$ for trend & $<0.001$ & 0.337 & 0.311 \\
\hline \multirow[t]{6}{*}{ Age $\geq 50$} & Underweight & $0.53(0.25-1.13)$ & $0.66(0.31-1.40)$ & $0.67(0.32-1.43)$ \\
\hline & Normal weight & Reference & Reference & Reference \\
\hline & Overweight & $1.15(0.93-1.42)$ & $1.13(0.91-1.39)$ & $1.12(0.90-1.39)$ \\
\hline & Obese, class I & $1.19(0.97-1.45)$ & $1.20(0.98-1.47)$ & $1.20(0.98-1.47)$ \\
\hline & Obese, class II & $1.34(0.91-1.98)$ & $1.37(0.93-2.01)$ & $1.38(0.94-2.03)$ \\
\hline & $p$ for trend & 0.012 & 0.015 & 0.015 \\
\hline
\end{tabular}

${ }^{*}$ Cox proportional hazards model unadjusted; ${ }^{\dagger}$ Cox proportional hazards model adjusted for age, income; ${ }^{\ddagger}$ Cox proportional hazards model adjusted for age, income, DM, hypertension, and dyslipidemia.

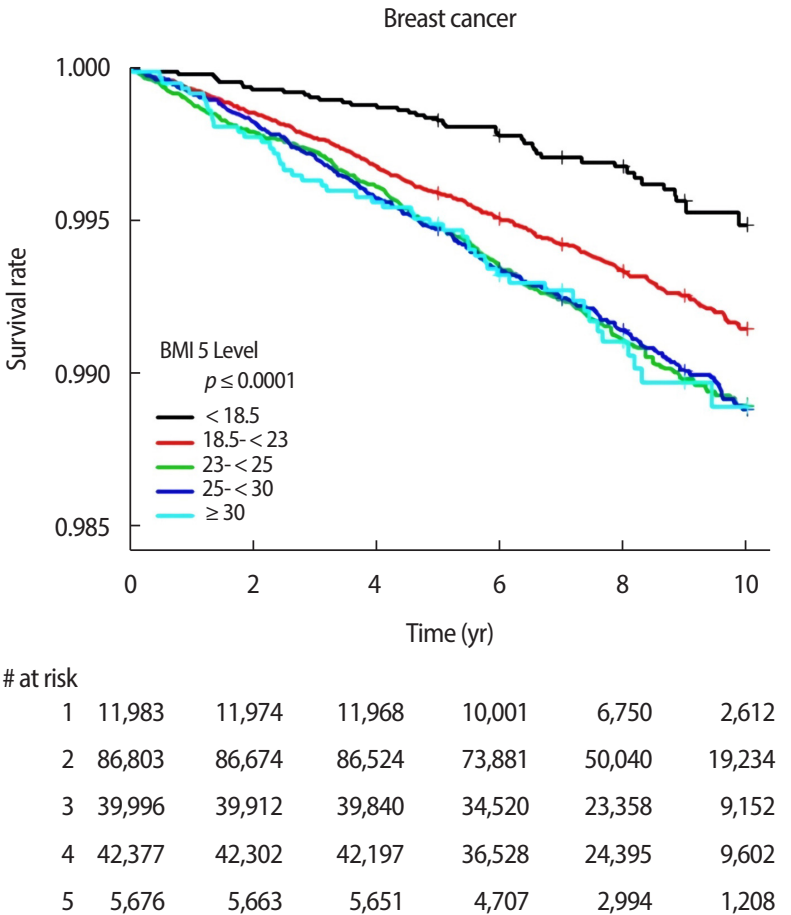

Figure 1. Breast cancer free-survival in each group of body mass index.

differences according to BMI $(p$ for trend $=0.3371$ and 0.3107 , respectively). Although neither unadjusted and adjusted HRs of BC in postmenopausal women were statistically significant, the $p$ for trend was

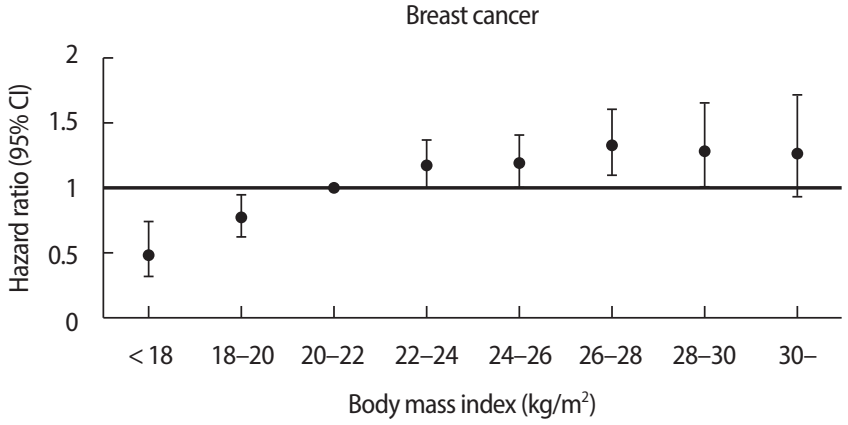

Figure 2. The relationship between body mass index and breast cancer risk.

statistically significant in each model $(0.012,0.015$, and 0.015 , respectively, Table 3)

Further examination regarding the association between other clinical variables, such as DM, HTN, and hypercholesterolemia, and BC development was conducted (Table 4). The results showed that pre-existing DM was inversely associated with $\mathrm{BC}$, corresponding to the adjusted HR of 0.70(95\% CI 0.52-0.94) for the pre-existing DM group, compared with those without DM. HTN also showed an inverse association with $\mathrm{BC}$, and comparison of the non-HTN group with the new HTN group and pre-existing HTN group produced an adjusted HR of 0.84 (95\% CI, 0.71-0.99) and 0.82 (95\% CI, 0.69-0.97), respectively. There was no significant association between hypercholesterol- 
Table 4. Cox regression analysis for association between breast cancer and $\mathrm{DM}^{*}$, hypertension, and hypercholesterolemia

\begin{tabular}{|c|c|c|c|c|c|c|}
\hline Variable & Event & Duration $(\mathrm{yr})^{*}$ & $\mathbb{I R}^{+}$ & Model $1^{\ddagger}$ & Model $2^{\ddagger}$ & Model $3^{\S}$ \\
\hline \multicolumn{7}{|l|}{ DM } \\
\hline No & 1,289 & $1,369,137.48$ & 0.94 & Reference & Reference & Reference \\
\hline New & 35 & $34,431.77$ & 1.02 & $1.08(0.77-1.51)$ & $0.98(0.70-1.37)$ & $0.96(0.68-1.34)$ \\
\hline Pre-existing & 48 & $60,170.83$ & 0.80 & $0.85(0.64-1.13)$ & $0.74(0.56-0.99)$ & $0.70(0.52-0.94)$ \\
\hline \multicolumn{7}{|l|}{ Hypertension } \\
\hline No & 1,014 & $185,499.92$ & 0.93 & Reference & Reference & Reference \\
\hline New & 159 & $174,900.98$ & 0.91 & $0.97(0.82-1.15)$ & $0.86(0.73-1.03)$ & $0.84(0.71-0.99)$ \\
\hline Pre-existing & 199 & $203,339.18$ & 0.98 & $1.05(0.90-1.22)$ & $0.88(0.75-1.04)$ & $0.82(0.69-0.97)$ \\
\hline \multicolumn{7}{|c|}{ Hypercholesterolemia } \\
\hline No & 1,168 & $1,251,585.84$ & 0.93 & Reference & Reference & Reference \\
\hline New & 129 & $138,780.95$ & 0.93 & $0.99(0.83-1.19)$ & $0.92(0.76-1.11)$ & $0.89(0.74-1.07)$ \\
\hline Pre-existing & 75 & $73,373.30$ & 1.02 & $1.10(0.87-1.39)$ & $0.98(0.77-1.25)$ & $0.91(0.72-1.16)$ \\
\hline
\end{tabular}

$\mathrm{DM}=$ diabetes mellitus.

*Person-years of observation (number of case $\times$ follow up period); ${ }^{\dagger}$ Incidence rate (per 1000) during follow-up period; ${ }^{\ddagger}$ Cox proportional hazards model adjusted for age, income; ${ }^{5}$ Cox proportional hazards model adjusted for age, income, DM, hypertension, and dyslipidemia.

emia and BC.

\section{DISCUSSION}

In this large cohort study, we investigated the association between obesity and BC risk in Korean women. Although the rate of obesity has increased in Korea, a majority of Korean women remain nonobese, and the prevalence of obesity is low in young women [3]. Considering that $\mathrm{BC}$ is observed in approximately $50 \%$ of premenopausal Korean women, the effect of obesity on BC in Korean women may be different from that in Western women. However, the results of this study were similar to the previous studies, showing a positive association between $\mathrm{BMI}$ and $\mathrm{BC}$, even in Korean women.

The effect of obesity on BC in postmenopausal women is not subject to significant debate. We confirmed a positive association between obesity and $\mathrm{BC}$ in postmenopausal women. Hypercholesterolemia associated with obesity increases the risk of BC through the production of estrogen via aromatization and through the effect of 27-hydroxycholesterol in postmenopausal women [12]. Obesity also dysregulates multiple biological pathways, including those related to inflammation, insulin resistance, and endogenous sex hormone synthesis $[13,14]$. Obesity-induced free insulin-like growth factor 1 is associated with increased risk of premenopausal and postmenopausal BC [15]. The potential mechanisms responsible for obesity suggest that obesity can increase the risk of $\mathrm{BC}$ development, even in premenopausal women. However, our study failed to show the association be- tween obesity and BC risk for Korean women.

Multiple inconsistent studies have been conducted to assess the association between obesity and BC risk in premenopausal women. Several studies show that obesity reduces the risk of $\mathrm{BC}[16,17]$, whereas others claim that obesity increases the risk of $\mathrm{BC}$ in premenopausal women [18-22]. It is difficult to explain the discrepancies in these findings because race, weight change, medication, and several other clinical factors can influence the results. A possible influence of medication was indirectly observed in the present study. Although DM is generally associated with $\mathrm{BC}$ [23], the results of the present study showed that pre-existing DM, but not newly diagnosed DM, was inversely associated with $\mathrm{BC}$, suggesting that DM medications such as metformin, which can reduce $\mathrm{BC}$ development, may have influenced the results.

Previous studies have demonstrated the importance of weight change on the risk of BC. Weight gain among women in their 40s increased the risk of pre- and postmenopausal BC [24]. In the Nurses' Health Study, recent weight gain over four years was associated with an increased risk of premenopausal BC, and the risk was greater for estrogen receptor (ER)-negative/progesterone receptor (PR)-negative and ER-positive/PR-negative disease than for ER-positive/PR-positive disease [25]. Although we could not confirm the change in weight for individual women or medications in the present study, we determined the potential risk of obesity associated with premenopausal BC using an unadjusted HR in the Cox regression analysis. However, the number of $\mathrm{BC}$ events in the present study was small, most notably in the 
obese groups, a limitation that could have influenced the results. Our definition of menopause is also a limitation of the present study. Although we defined premenopausal status as beginning at the age of 50 , several Korean women become menopausal in their 40s, and the average age at natural menopause in Koreans is approximately 49 years [26-29]. Further study using a larger population and more accurate measurements of menopause is required to determine the effect of obesity on premenopausal BC.

We demonstrated that increasing BMI is positively associated with $\mathrm{BC}$ in postmenopausal women using a Korean large cohort, although we failed to show the association between obesity and $\mathrm{BC}$ in premenopausal women. We suggest that a reduction in BMI may decrease the risk of BC in overweight or obese Korean women.

\section{CONFLICT OF INTEREST}

The authors declare that they have no competing interests.

\section{ACKNOWLEDGMENTS}

We thank Dr. Han from the Catholic University of Korea for his assistance in the statistical analyses.

\section{REFERENCES}

1. Oh CM, Won YJ, Jung KW, Kong HJ, Cho HS, Lee JK, et al. Cancer statistics in Korea: incidence, mortality, survival, and prevalence in 2013. Cancer Res Treat 2016;48:436-50.

2. Kim Z, Min SY, Yoon CS, Jung KW, Ko BS, Kang E, et al. The basic facts of Korean breast cancer in 2012: results from a nationwide survey and breast cancer registry database. J Breast Cancer 2015;18: 103-11.

3. Kim DM, Ahn CW, Nam SY. Prevalence of obesity in Korea. Obes $\operatorname{Rev} 2005 ; 6: 117-21$.

4. Renehan AG, Tyson M, Egger M, Heller RF, Zwahlen M. Bodymass index and incidence of cancer: a systematic review and meta-analysis of prospective observational studies. Lancet 2008;371: 569-78.

5. Key TJ, Appleby PN, Reeves GK, Roddam A, Dorgan JF, Longcope $\mathrm{C}$, et al. Body mass index, serum sex hormones, and breast cancer risk in postmenopausal women. J Natl Cancer Inst 2003;95:121826.

6. Berstad P, Coates RJ, Bernstein L, Folger SG, Malone KE, Marchbanks PA, et al. A case-control study of body mass index and breast cancer risk in white and African-American women. Cancer Epidemiol Biomarkers Prev 2010;19:1532-44.

7. Ogundiran TO, Huo D, Adenipekun A, Campbell O, Oyesegun R, Akang E, et al. Case-control study of body size and breast cancer risk in Nigerian women. Am J Epidemiol 2010;172:682-90.

8. Song SO, Jung CH, Song YD, Park CY, Kwon HS, Cha BS, et al. Background and data configuration process of a nationwide population-based study using the Korean national health insurance system. Diabetes Metab J 2014;38:395-403.

9. Lee J, Lee JS, Park SH, Shin SA, Kim K. Cohort profile: the national health insurance service-national sample cohort (NHIS-NSC), South Korea. Int J Epidemiol 2017;46:e15.

10. WHO expert consultation. Appropriate body-mass index for Asian populations and its implications for policy and intervention strategies. Lancet 2004;363:157-63.

11. WHO/IASO/IOTF. The Asia pacific perspective: redefining obesity and its treatment. Health Communications Australia. Melbourne: 2000.

12. Nelson ER, Wardell SE, Jasper JS, Park S, Suchindran S, Howe MK, et al. 27-Hydroxycholesterol links hypercholesterolemia and breast cancer pathophysiology. Science 2013;342:1094-8.

13. Healy LA, Ryan AM, Carroll P, Ennis D, Crowley V, Boyle T, et al. Metabolic syndrome, central obesity and insulin resistance are associated with adverse pathologic features in postmenopausal breast cancer. Clin Oncol 2010;22:281-8.

14. Shoelson SE, Herrero L, Naaz A. Obesity, inflammation and insulin resistance. Gastroenterology 2007; 132:2169-80.

15. The endogenous hormones and breast cancer collaborative group. Insulin-like growth factor 1 (IGF1), IGF binding protein 3 (IGFBP3), and breast cancer risk: pooled individual data analysis of 17 prospective studies. Lancet Oncol 2010;11:530-42.

16. Palmer JR, Adams-Campbell LL, Boggs DA, Wise LA, Rosenberg L. A prospective study of body size and breast cancer in black women. Cancer Epidemiol Biomarkers Prev 2007;16:1795-802.

17. Loi S, Milne RL, Friedlander ML, McCredie MR, Giles GG, Hopper $\mathrm{JL}$, et al. Obesity and outcomes in premenopausal and postmeno- 
pausal breast cancer. Cancer Epidemiol Biomarkers Prev 2005;14: 1686-91.

18. Mathew A, Gajalakshmi V, Rajan B, Kanimozhi V, Brennan P, Mathew BS, et al. Anthropometric factors and breast cancer risk among urban and rural women in South India: a multicentric case-control study. Br J Cancer 2008;99:207-13.

19. Cecchini RS, Costantino JP, Cauley JA, Cronin WM, Wickerham DL, Land SR, et al. Body mass index and the risk for developing invasive breast cancer among high-risk women in NSABP P-1 and STAR breast cancer prevention trials. Cancer Prev Res 2012;5:58392.

20. Sonnenschein E, Toniolo P, Terry MB, Bruning PF, Kato I, Koenig $\mathrm{KL}$, et al. Body fat distribution and obesity in pre- and postmenopausal breast cancer. Int J Epidemiol 1999;28:1026-31.

21. Tehard B, Clavel-Chapelon F. Several anthropometric measurements and breast cancer risk: results of the E3N cohort study. Int J Obes 2006;30:156-63.

22. Kang HS, Han J, Kim J, Lee HB, Shin H, Han W, et al. Analysis of the relationship between body mass index and breast cancer incidence in Korean women. J Breast Dis 2016;4:64-9.

23. Larsson SC, Mantzoros CS, Wolk A. Diabetes mellitus and risk of breast cancer: a meta-analysis. Int J Cancer 2007;121:856-62.

24. Vrieling A, Buck K, Kaaks R, Chang-Claude J. Adult weight gain in relation to breast cancer risk by estrogen and progesterone receptor status: a meta-analysis. Breast Cancer Res Treat 2010;123:641-9.

25. Rosner B, Eliassen AH, Toriola AT, Hankinson SE, Willett WC, Natarajan L, et al. Short-term weight gain and breast cancer risk by hormone receptor classification among pre- and postmenopausal women. Breast Cancer Res Treat 2015;150:643-53.

26. Park CY, Lim JY, Park HY. Age at natural menopause in Koreans: secular trends and influences thereon. Menopause 2018;25:423-9.

27. Park YJ, Kim HS, Kang HC. The age at menopause and related factors in Korean women. J Korean Acad Nurs 2002;32:1024-31.

28. Lee IS, Lee HH, Lee SM, Lee JJ, Nam KH, Lee SG, et al. A prospective population-based study of menopausal symptoms in Korean women. Singapore J Obstet Gynaecol 2001;32:54-8.

29. Shin A, Song YM, Yoo KY, Sung J. Menstrual factors and cancer risk among Korean women. Int J Epidemiol 2011;40:1261-8. 